DOI: 10.20472/IAC.2018.043.023

KIRAN KUMAR KOTHA

Indian Institute of Management Indore, India

\title{
MIS-PRICING IN SINGLE STOCK FUTURES: EVIDENCE FROM NATIONAL STOCK EXCHANGE OF INDIA
}

\begin{abstract}
:
We examine the determinants of mispricing in single stock futures traded in the National Stock Exchange of India, the second largest global trading venue for such contracts. We compute mispricing bounds using multi-regime models for over one hundred stocks. The size of the mispricing window - defined as the distance between these bounds - increases with decrease in liquidity. Liquidity of the futures market has a larger impact on the size of the mispricing window as compared to that of the spot market. After controlling for such liquidity effects, the size of the mispricing window is found to increase with increase in volatility. This suggests that concerns related to margin calls and execution shortfalls dominate early exit options. Volatility has an asymmetrical effect on mispricing bounds. We attribute this to short-sale constraints since they make the early exit option difficult to exercise when futures are under-priced.
\end{abstract}

\section{Keywords:}

Liquidity, Volatility, ShortSales

JEL Classification: G13, G14, G15 